\section{ON CARCINOMA OF THE LIVER.}

\section{By JOHN RICHARD WARDELL, M.D., F.R.C.P., Physician to the Tunbridge Wells Infirmary.}

G. B., a tall thin man 60 years of age, who had long pursued the occupation of a gardener, applied as an out-patient, May 7 th, 1867. Three years before that date he was stout and well furnished, and had always enjoyed good health. At that time, he had an attack of bronchitis, which was followed by a good deal of general debility. He lapsed into a state of continued indisposition, lost flesh, and became weak: he attributed this declension from his former robustness to indigestion, as the appetite failed, and he had a weight in the stomach after meals. He never had jaundice. For some time he had complained of this uneasy feeling of weight and heaviness, occasionally increasing into absolute pain, especially in the right hypochondrium and scrobiculus cordis. On admission, he had a markedly cachectic look, the sclerotics were blanched and bloodless, and the features shrunken, anæmic, and tinged with a dusky yellowish hue. He was evidently much emaciated, and the history of his ailment and present appearance very ominously pointed to malignant disease. The cardiac and pulmonary signs were natural; the pulse 80 , and regular, and the respiration 23 , easy and unembarrassed. On inspection of the abdomen, the epigastrium was full and prominent, and preternaturally resonant on percussion. The superficial abdominal veins were not notably enlarged. The ordinary hepatic lines of dulness were found to be exceeded at the right mammary and axillary lines, and the free margin of the right lobe of the liver could be distinctly felt a couple of fingers' breadth below the right false ribs. Between the costal cartilages and the mesial line pressure at once gave pain. He said that the sense of weight and fulness in this situation had latterly become far more urgent, and that the pain and flatulence now occasioned a good deal of distress. He sometimes had sickness and vomiting. The tongue was covered with a thin creamy fur, its edges being pale and indented. The bowels were and had been constipated; and the alvine dejections generally exhibited a deficiency of bile-pigment. The urine, with the exception of containing bile and an excess of lateritious and some purpurous deposits, presented no other abnormal characteristics under the ordinary tests. $\mathrm{He}$ was for some weeks treated with cinchona, hydrocyanic acid, belladonna, bismuth, lime-water, and the alkalies in combination with various bitter infusions, and occasional opiates; and the bowels were, from time to time, relieved by mild aloetic medicines. $\mathrm{He}$ was placed on a regulated diet, and he took a moderate allowance of wine. Under this treatment, for a time, he expressed himself as being decidedly benefited, but, as I had anticipated, the relief was only temporary; the gastric symptoms were not really ameliorated, and the tissue-waste evidently continued: $\Lambda$ t length he became unable to come to the Infirmary, and he was subsequently attended at his own home by the House-Surgeon, Mr. F. Manser.

On July 28 th, he was in a very weak and an emaciated condition. He complained much of great weight and fulness at the pit of the stomach and in the right side. The attacks of sickness and vomiting were more frequent, and the retention of his food had become much more difficult. The edge of the right lobe of the liver projected fully three inches below the costal margin. There could, at this date, be distinctly felt two nodules, which were hard, smooth, of spheroidal configuration, of the size of a Spanish nut; and these were manifestly situate on the convex surface of the liver. There was no particular bulging of the organ, but, as above remarked, it abnormally depended. The superficial abdominal veins were full and easily traced, but not so turgid as to indicate any great amount of portal obstruction. $\mathrm{He}$ had not much pain on moderate pressure, but the jar of percussion at once gave pain. $\mathrm{He}$ was ordered hydrocyanic acid, morphia, alkalies, and opiate and belladonna epithems; and the pain and sickness were relieved by these remedies. He gradually declined, and died August II th, I867.

The examination was made on August 1 $3^{\text {th }}$, forty-eight hours after death, the autopsy being performed by Mr. Manser. The body was greatly emaciated, and the surface generally tinctured with a dusky yellowish tinge. On opening the abdomen, no serum flowed from the incision, but a small quantity of effused yellowish green fluid was contained in the abdominal cavity. The stomach lay in its proper position, but was smaller than in health; and, on removing it, its parietes were found to be much attenuated, and the orifices normally patulous. The liver was large, and occupied considerably more than its usual space; it covered the stomach, filled up the left hypochondrium, and protruded very notably below the thoracic border. Its convex and concave surfaces were crowded with round spheroidal or ovoid clearly defined nodules, which were of a yellowish straw or fawn colour. Some of these tumours were slightly elevated and perceptibly flattened or indented; and, where these flattenings and indentations were in apposition to the hepatic peritoneum, the serous membrane was less transparent or more milky looking than where it indued the intervening and natural surface of the organ. The nodules varied greatly in size, some being not larger than a swanshot, a pea, or a hazel-nut, others being as large as a filbert or a pullet's egg. They were slightly adherent to the peritoneal investment by a delicate diaphanous filamentous structure. On removing the liver, and making numerous sections of its substance, these heterologous masses were found in every part of the viscus, differing in size in the same manner as they differed in size on the surface. Each growth, on careful examination, was found to be enveloped in the fine transparent investment above described, which constituted an easily divided band of union between the morbid product and the hepatic parenchyma. The formations were so numerous as to have very obviously encroached upon and abolished much of the tissues in which they were deposited. On cutting them open, the divided surfaces very closely resembled the colour of their superficies. Their consistence was that of old cream cheese; they were quite homogeneous, devoid of vascularity or other conditions of organisation. There were no fibrous zeolite-like radiations from one or more central points towards the periphery which these bodies sometimes present, nor yet any fractuous lines passing through their substance. They bore moderate pressure between the fingers, but were more or less friable. Portions of these depositions being placed under the microscope exhibited an abundance of nucleated, elongate, or caudate cells, free nuclei, cells containing bile-pigment, a few scattered plates of cholesterine, some amorphous granular matter, and innumerable fat-molecules.* The intervening hepatic parenchyma was of dirtyish light red colour. The ducts were pervious, and the gall-bladder was small and filled with light-yellow bile. The spleen was small, and, on being divided, its central portion was dark, pulpy, and semi-diffluent. The pancreas was atrophied, but not indurated. The kidneys were normal. The gastro-hepatic omentum was utterly devoid of fat, and had assumed the appearance of a red fibro-vascular membrane. On close examination, it contained innumerable small, hard, granular bodies, varying from the size of a millet-seed to that of a pea, and the microscope showed them in their elementary constituents, though of more fibroid tendency, to resemble the ultimate cellular and molecular components of the larger morbid products discovered in the liver. The other abdominal organs were healthy. The thoracic viscera were not examined.

The above recorded case is a typical example of one species of carcinoma not unfrequently discovered in the liver, and which recent writers on pathological anatomy have described with much accuracy. The morbid conditions of this organ during life are often, even under the eye of the most expert diagnostic, amhiguous and difficult; and the causes of this want of certitude in the distinguishment of hepatic complaints can, upon a cursory reflection, be well understood. The viscus, in its healthy condition, by lying beneath the concave surface of the diaphragm, and under the thoracic wall, is almost as hidden from sight and touch as the encephalic mass is hidden by the cranium. Again, it may be gravely affected without its normal lines of dulness being extended; or there may be a greater or less degree of its dislocation, simulating tumescence, when it is in nowise diseased. Its enlargement may be resembled when empyema of the right thorax pushes down the diaphragm, when an encysted kidney is in apposition with its lower margin, in organic diseases of the stomach, and in cancer of the omentum. Malignant disease may be imitated by an impacted colon, by hydatids, and by tropical and pyæmic abscesses. Sometimes tumours will be formed in the right hypochondrium with such rapidity as to confer doubt as to their hepatic origin, and sometimes fundamental and fatal changes may have been established in the substance of the liver, when the outward and visible sign of jaundice has not been apparent; or there may be hyperæmic tumidity and icterous discoloration when the disorder is functional and comparatively unimportant, and when no organic mutations have been instituted. The form of the liver may be varied by tight lacing, and by abnormal configuration of the lower part of the thorax; and its axis may be altered by the accumulation of gas in the stomach and intestinal canal, by ascites, by pericardial effusion, and by pulmonary emphysema. That renal should have been rendered far more precise and perfected than hepatic pathology may be easily comprehended, when it is taken

* In this particular kind of carcinoma of the liver, minute inspection discovers the malignant bodies of every size down to those of microscopic dimensions. Indeed between the rudimentary nucleated cancer-cells and the normal hepatic cells there is little physical, if any absolutely cognisable, difference. In the fungoid and encephalomatous varieties, the cells are generally larger than the hepatic cells. 
into consideration that the ultimate structure of the kidney is less complicated, that its secretion can be obtained without admixture and with facility, and subjected to chemical and microscopical examination, which is not the case with the bile, and that the morbid products, from which essential inferences may be deduced, are contained in the uriniferous tubes. And, if a passing comparison be made between the other larger solid organ-the spleen-and the liver, in respect to pathologic recognition, it may be held as a rule that absolute enlargement, cognisable and often very manifest, is the common condition of splenic disease, because its distensible trabeculæ and pulpy structure, under nearly all forms of its morbid state, render it prone to hyperæmia ; and, when chronically affected, as in hypertrophy and purulent accumulation, the history, physical signs, and objective symptoms commonly conduct to a correct diagnosis.

The history and symptoms of this man were such as sample closely with what obtains in the ordinary illustrations of the complaints. His once healthy aspect and robustness of conformation prove, as I have in repetition observed, that cancer does not always, as was formerly supposed, come on in such as are of frail and delicate constitution. I have before repeatedly known those who were models of muscular power, and those who have been the verisimilitude of florid, well-furnished healthiness, become the prey of this fell and implacable disease. There is no doub that the bronchitic attack, by its induction of general debility, disordered digestion, and consequent malassimilation, favoured the development of this morbid process, where the diathetic tendency already existed, and needed but some cause of declension of vital power to act proximately and bring it into noxious existence. The feeling of weight and fulness in the right hypochondrium, the impaired appetite, the flatulence and the hypochondriacal depression, were symptoms highly characteristic; and they are generally experienced in the earlier and more obscure stages of the malady, before any tumour can be recognised, and when it is impossible to declare the real nature of the lesion. The non-febrile condition, the cachexia, and the loss of flesh were significant facts, as they should ever be regarded in such cases. That the liver was large when he first came under my care, palpation and percussion at once rendered evident; but its free border was then smooth and rounded, and such enlargement might be from causes other than malignant deposit, and from this symptom alone a correct diagnosis could not be inferred. He had not had jaundice; but the absence of that symptom counted for little in the consideration of his ailment, because in cancer of the liver it often happens-indeed, it most frequently happens-that icterus does not, from the beginning to the end, supervene. The organ may be rendered three times its normal size from cancerous deposition, and no jaundice be produced. Frerichs says that it is of little value as a symptom, because it is not present in the majority of cases; and, of ninety-one examples of cancer of the liver, given by this authority, in fifty-two jaundice never came on. Of course this event often depends upon the fortuitous circumstance of the heterologous growth pressing upon one or more of the larger ducts ; and when it does occur, it never disappears. There may, however, be what Virchow terms hæmatogenic icteruswhen it is of blood-origin, an event which this writer considers to be caused by the disintegration of a large number of blood-corpuscles. (Virchow's Arch. xxxii Heft. 1865). Sometimes a carcinomatous live may not be at all enlarged, and a small cancerous mass may be formed within or press upon a duct and cause such obstruction as to give rise to intense jaundice; and sometimes there may be very obvious extension of the hepatic lines of dulness, and great hyperæmia of the viscus consequent upon the pressure of malignant tumour of the stomach, peritoneum, or pancreas, when hepatic cancer is greatly simulated. An apt illustration of what is now asserted was some time ago presented to my notice. A farm-servant, 52 years of age, was admitted into one of my beds in the Infirmary in April I 867 ; and I at once regarded his case as that of malignancy. He had some slight pain at the epigastrium, but did not complain of sickness; he had a dusky, cachectic aspect, had lost flesh, and was hecoming anasarcous. The liver was large, the right mammary line was exceeded, the free border was below the costal edge; the stools were clay-coloured, and the urine contained bile. In the last days of June he became jaundiced; and this symptom, which was strongly marked, continued to the time of his death, which occurred July 12th. The presence of primary or secondary cancer in the hepatic substance was not altogether improbable, from both negative and positive facts ; because there had been no broadly marked indications of carcinoma of the stomach, nor could any distinct tumour at the pylorus or other part be felt ; because there was little or no epigastric pain, no sour eructations, no sickness; because there had been dull, heavy, dragging pain in the right hypochondrium darting up into the shoulder; and because the liver depended below the costal margin, and deep persistent jaundice came on. The autopsy, however, exhibited, not hepatic cancer, but pyloric cancer which mechanically obstructed the vena portæ and choledochus duct. The liver was large and extremely hyperæmic, but no trace of malignancy could be found in any part of its parenchyma. The dropsy and jaundice were at once explicable.

[To be concluded.]

\section{ON THE DANGER TO LIFE FROM LIMB-AMPUTA- TION IN ST. BARTHOLOMEW'S HOSPITAL.}

\section{By HOLMES COOTE, EsQ.,} Surgeon to the Hospital.

I TRUST that Sir James Simpson will not think me guilty of want of courtesy in not having sent an earlier reply to his last communication. I still maintain that in London and in other cities there is a necessity for us to aggregate our sick in large hospitals; for I know not where we are to find space enough or money enough to erect a number of detached cottage-hospitals, with all their accessories, standing in their own grounds. That which is possible in America may not be possible here, unless indeed we take to purchasing, for the benefit of the sick poor, the parks of the country gentry, and convert them into convalescent establishments. The sick poor, did I say? " the self-constituted pauper sick" would be a more appropriate term. It was but to-day that heard of a "pauper" patient assuring his life for two thousand pounds in the same office where the doctor who gave him gratuitous advice was glad enough to assure his life for two hundred. Each hospital we establish spreads ruin far and wide upon the members of our profession. I heard as a fact that the establishment of the Great Northern Hospital (no such large institution) caused three hundred small practitioners and chemists and druggists to shut up their shops. At all events, it is known that they closed their accounts at a large wholesaledruggist's and migrated elsewhere.

But, to return to facts of surgical statistics, Sir James Simpson must confess that it is a habit (and a very legitimate habit) for country practitioners to send their worst and most hopeless cases to the London hospitals. The cases are always worse than those seen elsewhere; consequently the comparison as to the death-rate between town and country is scarcely fair.

In the next place, I think that Sir James makes the London deathrate too high. For other purposes, and indeed before I had ever seen Sir James's interesting letters, I had taken a list of all the serious operations performed by myself in St. Bartholomew's Hospital for the year 1864. They were as follows: Amputations of the thighs, 3-all recovered; amputations of the leg, 3-onedied; extirpation of the breast for cancer, I-died ; she was near 70; ligature of the femoral artery, 2-both recovered; amputation of the arm, 7-all recovered ; cancerous tumours, 2 -both recovered. This makes 18 cases of operations of first magnitude and 2 deaths, or $I$ in 9. I will, if so wished, give similar statistics for the succeeding years; but this may suffice to shew that we do not lose patients at the rate which other statistics might lead one to infer.

But in the very instance of amputations of the thigh, statistics may lead us far from the true conclusion. "The proportion," says Sir James, "of traumatic thigh-amputations, as compared with other limb-amputations, is smaller in St. Bartholomew's than it is in the statistics of rural practice which I have collected." Against 24 cases of amputation performed at St. Bartholomew's by all the surgeons during a certain period, Sir James puts 22 cases performed by one individual surgeon, and 20 cases performed by another! We may well ask, Are cases requiring amputation of the thigh so much more common in a sparse rural population than in manufacturing London, with its four million of inhabitants? or do some surgeons amputate more readily and under more favourable cases than others? Where is it, in town or in country, that the greater number of injured limbs are saved altogether from operation?

I will not follow this reasoning further, because I am quite prepared to agree with Sir James Simpson thus far, that it is unwise to assemble tngether too many sick, and that a vast number of patients are indeed gasping for country air. The plan now advocated in London to establish convalescent hospitals will meet this emergency. May they not spread ruin among the rural doctors where they are about to be placed! I will go further, and confess that all sick persons will improve more rapidly, when improvement is possible, by putting them into well-placed detached cottages, surrounded by every luxury, in pure and bracing air with the best medical advice, gratuitously bestowed. But even wer this practicable, which it is not, it would not do away with the necessity of the London hospitals; and I know of no plan better than that upon which St. Bartholomew's is constructed; namely, four detached buildings in the form of a square, raised in stories on an elevation just above that of surrounding buildings. 